кУльтУРОЛОГИЯ

DOI: $10.17805 /$ trudy.2015.5.7

\title{
РУССКАЯ ТРАДИЦИОННАЯ ТАНЦЕВАЛЬНАЯ КУЛЬТУРА: ИСТОКИ И СОВРЕМЕННОСТЬ
}

\author{
А. А. Чистякова \\ (Московский гуманитарный университет)
}

Аннотация: В статье анализируется тема возникновения русской традиционной танцевальной культуры, которая ведет отсчет от русско20 плясового фольклора. Отмечается, что традиционная народная пляска это особая форма выражения чувств и сознания человека; способ национального самовыражения, коллективного творчества.

Ключевые слова: русский танец; танцевальная культура; традиционный танец; плясовой фольклор; история русского танцза

\section{THE CULTURE OF TRADITIONAL RUSSIAN DANCING: ORIGINS AND MODERNITY}

\author{
A. A. Chistyakova \\ (Moscow University for the Humanities)
}

\begin{abstract}
The article examines the origins of traditional Russian dance culture, which stems from the Russian dance folklore. We treat traditional dancing both as a special kind of expressing feeling and human consciousness and as ethnic self-expression and collective art.
\end{abstract}

Keywords: Russian dancing; dance culture; traditional dancing; dance folklore; history of Russian dancing

Русское хореографическое искусство известно и высоко ценится во всем мире. Русский балетный театр, отечественные профессиональные и самодеятельные коллективы пользуются огромной популярностью, выступления русских артистов на конкурсах и фестивалях за рубежом, а также с сольными концертами получают высокие оценки жюри и признание зрителей: «Вдохновенные, навеянные древними легендами различных уголков России танцы «Гжели» (Московский академический театр танца «Гжель». - A. Ч.) поражают великолепной хореографией и фантастическим исполнением солистов, а также их грандиозными, ни с чем не сравнимыми костюмами. Это спектакль необычайной красоты, восхищающий публику как музыкой, так и величием народа, создавшего ее. Невероятное кружение, полное цвета и динамизма, смены настроений, нежности 
и сияния, покоряющего всех, кто видел это чудо» (Сказочная гжель Владимира Захарова ..., 2004: 235).

Веселые, задорные, грустные, лирические танцы сменяют один другой. Посмотришь на русские танцы - словно по России прокатился. Одна из парижских газет написала: «Достаточно увидеть хотя бы один концерт “Березки”, чтобы узнать Россию. В танцах актеров - русский нрав, сила и красота народа» (Конодюк, Электр. ресурс).

Отличительными чертами русской танцевальной школы является духовная красота и сила, тонкий лиризм и целомудренность, высокое благородство, искрометная энергия, виртуозная выразительная техника, богатство и разнообразие форм танца. «Ни у одного народа нет пляски более выразительной, нежели национальный русский танец, - пишет немецкий публицист и ученый И. Беллерман. - Русский национальный танец столь красноречив, что я не знаю ему равного...» (цит. по: Гозенпуд, 1958: 222).

Многочисленные виды и жанры современного отечественного танцевального искусства берут свое начало в далекой древности - в русском плясовом фольклоре. В Лаврентьевской летописи мы можем найти описание стихийных языческих празднеств, на которых встречались различные племена - «межюселы, схожахуся на игрища, на плясанье». Древнеславянские сходы представляли собой яркое грандиозное театрализованное зрелище. О чем говорят площади культовых мест и названия праздников: «Собор», «Игрище», «Купало» (вкупе), «Собутка» («Событка», «Субботка») (Полное собрание русских ..., 1997).

В исторических и этнографических материалах мы найдем множество примеров, красочных описаний бурного темперамента наших предков, тяготении и пристрастии к пляске. Геродот, посетив северные берега Черного моря и познакомившись с порядками и бытом славянских племен, приходит к выводу: племена эти ведут образ жизни, какой указала им природа страны. Весьма созвучно этому заключению описание быта и нравов славян выдающегося русского историка Н. М. Карамзина «житель полунощных земель любит движение, согревая им кровь свою; любит деятельность; привыкает сносить частые перемены воздуха, и терпением укрепляется» (Карамзин, 1989: 62). Характеризуя нравы и быт славян, Н.M. Карамзин особо отмечает страстную любовь к пляске, которая «... состоит в том, чтобы, в сильном напряжении мышцей, взмахивать руками, вертеться на одном месте, приседать, топать ногами, и соответствует характеру людей крепких, деятельных, неутомимых» (там же: 70).

Музыка и танец сопровождают славянина во всех делах, на протяжении всей жизни: рождение, свадьба, тризна, счастливая охота, сбор плодов, военный поход, мир и встреча с дружественным племенем, наступление весны, обильный пир и т. п. все вызывает потребность в пляске, 
ритмически организованных движениях, поднимающих дух, демонстрирующих коллективную сплоченность.

В памятниках славянского искусства вместе с изображением сакральных символов воды, земли, солнца, дождя самое видное, значительное место занимают пластические и графические изображения танцующих людей. В разных кладах VII-VI вв. до н. э. на праславянской земле встречаются изображения девушек и женщин, исполняющих магический «танец плодородия». Подобный мотив - девушка, протянувшая руки к небу или к солнцу, распространен в русской вышивке XIX в. Археологические источники описывают отдельные женские фигурки «под дождем»: на сосудах среди дождевых полос и колосьев ритмично танцующие девушки, обвитых зелеными ветками и священными травами. Изображение символизирует земледельческий обряд «Русальские празднества», на которых дружины специально подготовленных танцоров и музыкантов, отличающихся высокой нравственностью, своим искусством должны были ублаготворить русалок и тем обеспечить хороший урожай. У западных славян таких девушек называли додолами, у восточных - «русальцы». Обряд сохранился до конца XIX в.

Особый интерес представляют литые серебряные фигурки четырех мужчин в национальной русской одежде, найденные в кладе VI в. н. э. на киевской земле. Положение рук мужчин - «подбоченившись» и позиции ног, определенно, указывающие на традиционное движение русской пляски - присядку. Если обратиться к полевым этнографическим материалам и документальным видеозаписям, сделанным в XX в, обнаруживается удивительное сходство рисунка поз, положения рук в древнеславянских танцах с положениями и движениями рук в традиционных народных танцах Центрального, Южного, Западного регионов России. Это свидетельствует о большой жизнеспособности народных форм танца.

История русского народного танца неразрывно связана с историей русского народа и несет на себе отпечаток его национального характера и условий его жизни. Структурные единицы танца: ритм, движения, мимика, композиция, костюм, в народной пляске несут определенную смысловую нагрузку, выступают как первичный символический язык человека. И в этой связи примечательно, что символические жесты и движения, в отличие от мимических движений лица, сходных у всех народов, при выражении чувств и эмоций, не представляют полного тождества. У разных народов они проявляются в своих характерных формах, сообразно климатическим и другим условиям жизни, а также и согласно различному пониманию душевных настроений и ощущений (Худяков, 2010: 14). Например, русский человек при подтверждении чего-либо кивает головой, при отрицании - машет в разные стороны, те же движения у болгар име- 
ют противоположное значение. Этнические различия заметны и в сходных по форме движениях, например, если сравнить русские присядки с греческими или присядками обских угров - одинаковые по названию движения имеют разный характер и абрис (внешнее очертание).

В соматических (телесных) движениях человека отражается этническая ментальность человека, танец несет отпечаток архаичных коллективных представлений. Символика обрядовой пляски, древнейшая из социальных знаковых систем, подсказала пути формирования человеческой речи. Символы не только служат обозначением и выражением мысли, но прежде всего, являются средствами создания мысли. Анализ словаря во многом отражает особенности культуры, а также - признаки местности, климата, занятий и ценностные ориентаций народа. Эти особенности мы можем заметить и в терминологии русского танца, например, в наименовании танцевальных движений: «гармошка», «елочка», «трилистник», «ястреб», «волчок» и т. п.; в названии танцев - «Просо», «Капустка», «Веретенце», «Полянка», «Подгорная», «Змейка», «Плетень», «Барыня» и др.

Каждый народ, преломляя архетип через свой стиль жизни и картину мира, рождает наиболее свойственные его духу образы и идеалы. Так, архетипом, объединяющим русских людей, выступает образ МатериЗемли - символ материнства, прародительницы и кормилицы всего живого: «Мать Сыра Земля», «Родная Земля», «Святая Земля». «В контакте с Землей» исполняются все традиционные русские пляски: это и плясовой (шаркающий) шаг, и многочисленные дроби, «моталочки», «ковырялочки» и т. д. Магический смысл танца, одного из самых древних видов народного творчества, - помощь земле, способность воздействовать на природу, перераспределять ее жизненные силы.

В связи с этим, мы можем вспомнить, существующий у славян запрет бить землю палкой и чем-либо иным, поскольку этим можно оскорбить умершую мать, похороненных предков. Не позволялось пахать, вбивать колья и другие подобные действия, тревожащие землю до наступления весны (схода снега, в христианстве до Благовещения), и, напротив, с приходом весны, как символ ритуального пробуждения земли, исполняли обрядовые пляски, один из основных элементов которых - пересек (наложение дробных выстукиваний разных групп, танцующих друг на друга).

Глубоко укоренившийся в русском сердце образ Белой Березы - символ русской природы, чистоты и святости, целомудренной красоты русской девушки. Как величественны и поэтичны весенние хороводы девушек с троицкими традициями кумиться (родниться), завивания венков и украшения березки.

«Плывет лебедушкой», «выступает словно пава» - в женском танце находит выражение архаичный образ девушки-птицы, дочери Окиянморя, олицетворяющей стихии воды и воздуха и обладающей особой пле- 
нительной совершенной красотой, жизнеутверждающей, оберегающей силой Девушки-лебедушки, утушки, голубушки часто встречаются в русской мифологии и сказках, в русских песнях. Эти народные мотивы отражаются в произведениях русских классиков (П. Чайковский балет «Лебединое озеро», А. Пушкин «Сказка о царе Салтане», М. Фокин - А. Павлова «Умирающий лебедь» и др.). Ясным Соколом взвивается в безудержной, лихой, виртуозной пляске молодец. «То не ясный сокол летает, то казак сердечный с добрым конем гуляет»- поется в песне. Мужская пляска отличается наличием сложных коленцев и элементов боевой подготовки. Ясный сокол в славянской мифологии связан с понятиями свет, свобода, Солнце - это символ богатырской силы, разудалого доброго молодца, защитника Земли Русской.

Выявление семантических основ русской танцевальной культуры приводит к выводу: традиционная народная пляска - это особая форма выражения чувств и сознания человека; способ национального самовыражения, коллективного творчества - в ее базовых средствах выражения (ритуальное соматическое действие, вербальные формулы, мифологические представления) заложены основы этнической культуры славян, отражаются черты национального характера и менталитета.

Изучение и освоение традиционной народной пластики способствует глубинному, многомерному постижению русской народной традиционной культуры, воспитанию гражданственности, любви к Родине; передаче нравственно-этических норм и социального опыта, норм индивидуального и общественного поведения; достижению гармонизация внутреннего мира отдельного человека и межличностных связей внутри социума в целом.

Сохранение и развитие исконно народных традиций, приобщение детей и молодежи к национальной культуре позволяет преодолеть унификацию культурных различий в современном глобализирующемся мире.

\section{СПИСОК ЛИТЕРАТУРЫ}

Гозенпуд, А. (1958) К истории балетного театра XVIII века // Ученые записки Гос. НИИ театра, музыки и кинематографии. Т. 2. С. 222

Карамзин, Н. М. (1989) История государства российского : в 12 т. / под ред. А. Н. Сахарова. М. : Наука. Т. 1.

Конодюк, О. Чем ансамбль «Березка» покорил весь мир? [Электронный ресурс] // Школа жизни.Ру. Познавательный журнал. URL: http:// shkolazhizni.ru/archive/0/n-21254/ (дата обращения: 12.04.2015).

Полное собрание русских летописей (1997). М. : Типография Эдуарда Праца. Изд. 4. Т. 1. Лаврентьевская летопись.

Сказочная гжель Владимира Захарова = Fairy-Tale Gzhel Vladimir 
Zakharov(2004) / сост.: В. В. Дегтярева, В. М. Казанцев ; ред., авт. стихов и лит. текста: Л. Н. Михеева ; пер. на англ. Елены Гражинской. М. : Редакция журнала «Балет».

Худяков, С. Н. (2010) Искусство танца: История. Культура. Ритуал. М. : Эксмо.

Чистякова Анастасия Александровна - доцент кафедры культуры и искусства Московского гуманитарного университета. Адрес: 111395, Россия, г. Москва, ул. Юности, д. 5. Тел.: +7 (499) 374-59-40. Эл. адрес: kalinkahm@mail.ru

Chistyakova Anastasiya Aleksandrovna, Associate Professor, Department of Culture and fine arts, Moscow University for the Humanities. Postal address: 5 Yunosti St., 111395 Moscow, Russian Federation. Tel.: +7 (499) 374-59-40. Email: kalinka-hm@mail.ru 